\title{
Editorial commentary on the state of clinical genetics in Brazil exemplified by the article on prenatal diagnosis by Kessler et al. Genetics and Molecular Biology (this issue)
}

\author{
Peter Pearson $^{1}$ \\ Departamento de Genética e Biologia Evolutiva, Instituto de Biociências, Universidade de São Paulo, \\ São Paulo, SP, Brazil.
}

As a relatively recent immigrant from Northern Europe, United Kingdom via the Netherlands, two countries both benefitting from well organised clinical genetic services, it is a great puzzle and worry to me why clinical genetic services, particularly in the public sector, are so badly organised in Brazil. Of course, the short answer is, the field is grossly underfunded. But underlying that simplistic conclusion is the undeniable fact that the Brazilian Ministry of Health at the federal level and various other bodies at the state level have failed to recognise the public health care value of establishing well-organised genetic screening and counselling facilities. Although Brazil can be justly proud of its health care position and initiatives in combating HIV infection and poliomyelitis, amongst others, its record on establishing well-organised and regulated genetic services with appropriate attention to training and professional recognition of genetic counsellors, cytogeneticists, molecular geneticists etc., falls far, far short of what is required and would be acceptable in most other countries.

The de facto situation is that anybody with a medical degree can put up a shingle claiming to carry out genetic diagnosis irrespective of training or specialist background. This is a legal loophole, which does not do justice to the technical requirements for genetic diagnosis and counseling or give professional recognition to the people really required to carry out the analyses, who are not usually not medically qualified and learnt their trade in Biology and related areas. Further, the current situation does not require diagnostic centres to provide evidence of proficiency, to submit annual returns on productivity or participate in quality control trials. The rich, particularly in large conurbations such as São Paulo, Porto Alegre, Rio de Janeiro etc.,

Send correspondence to Peter L. Pearson. Departamento de Genética e Biologia Evolutiva, Instituto de Biociências, Universidade de São Paulo, Caixa Posta. 11461, 05422-970 São Paulo, SP, Brazil. E-mail: peterlpearson@uol.com.br. are well catered for by private clinics, albeit without any traceable quality control by governmental agencies. Although a few of the private laboratories take part in international quality control programs, this is commercial window dressing and at a national level undesirable. What selfrespecting Ministry of Health leaves it to foreign organisations to carry out the quality control work that they should be performing themselves? In Brazil, the basic maxim is, if you can pay for it, then you can get it. The vast majority of the population are either excluded financially from making use of private clinics, or are unaware of the health risks ensuing from genetic disease or find great difficulty in finding a centre prepared to undertake genetic investigation free of charge. And even in situations where the government have taken steps to provide genetic testing within the public sector, such as post-natal chromosome diagnosis, the established level of remuneration is so low, that the diagnostic laboratories cannot afford to carry out cytogenetic analyses without a further source of income to cover the costs. Most or all genetic diagnoses carried out in the public sector in Brazil occur in public universities by people who are already overburdened by teaching and trying to do research, let alone run a genetic service as well. Most receive no remuneration for this and their limited time is donated freely to keep the services running. The bottom line is that the available capacity is far too small for the number of requests and only a small proportion of all applicants actually receive attention within a short period of time. In short, genetic testing within the public health care sector cannot and never will take place adequately without extensive governmental planning, reorganisation and introduction of adequate financial incentives.

Chromosome prenatal diagnosis is now a wellestablished procedure and passed out of the realms of being experimental more than 15 years ago in most of the developed world. Why then should the GMB choose to publish an article on this subject at this juncture (Kessler et al.,

1 The writer is one of only two genetic diagnosticians to have been certified for both molecular genetic and cytogenetic diagnosis in the Netherlands. He was the chairman of the Departments of Human Genetics within the medical schools of Leiden and subsequently Utrecht in the Netherlands and was a member of the Dutch ministry of health committee that formulated the genetic health care plan practised in the Netherlands today. He helped negotiate the logistics of financing genetic services with the health care insurers. He is not medically qualified. 
2008)? There are two reasons for doing so: through lack of any official avenue for cytogenetic centres to disclose productivity and efficiency rates, the article permits this particular group from Porto Alegre to present its results on carrying out chromosome prenatal diagnosis in the public health-care sector and for the results to be evaluated by others; secondly the article points to many of the inadequacies in Brazilian genetic screening services, not from the point of view of the efficiency of the Porto Alegre group itself, which succeeded remarkably well under the circumstances, but with the problems encountered on the way. Firstly, there are very few centres performing chromosome prenatal diagnosis in the public sector and many of the patients have to travel large distances. The work is specialised and labour intensive. This group was fortunate in that their hospital was prepared to fund the screening, probably accounting why the group could maintain its activities for the 18 year period described in the article. The lack of governmental financial support is one of the main reasons why so few groups are active with chromosome prenatal screening, despite an ever increasing need as physicians and the Brazilian public at large become increasingly aware of the diagnostic possibilities. Of course this situation begs the question of why one would even bother to carry out chromosome prenatal diagnosis when induced abortion is still illegal in Brazil and likely to remain so for a long period of time, but not for ever. Even the prototypically Roman Catholic country Italy legalised abortion 30 years ago despite ongoing controversies and attempts to reverse the law to this day. However, the straight answer for the current Brazilian situation is that knowing before a baby is born that it carries a chromosome abnormality, mentally prepares the parents beforehand on what they can expect at either miscarriage or birth of their child. In countries where induced abortion is legal, prenatal diagnosis is rarely refused even when the parents announce before hand that whatever the outcome, they will not have the child aborted: the parent's right to know what is in store for them is regarded as sufficient grounds for carrying out chromosome prenatal diagnosis.

How can the Brazilian situation be improved? Since 2004 a working group, composed of members from the two Brazilian Society of Genetics and Medical Genetics, respectively, and technical staff from the Ministry of Health have evaluated the potential need for genetic services nation-wide and drawn up guidelines on minimal requirements for infrastructure and financial commitments. The group also formulated a proposal for setting up a national policy for clinical genetics in the public sector, which includes publicity campaigns on prevention and education directed not only to the general public but also to health professionals. The Ministry of Health should be responsible for setting up such policy as well as monitoring the quality through annual reports. However, 4 years is a long period of time and the crucial question is when will the Ministry of Health finally start making use of the recommendations of the committee and legalise implementation of a Brazilian national program in genetic health care? I would suggest also that, following implementation of the plan the derived criteria of quality control and reporting also be extended to the private sector and make them obligatory for all private centres to stay in business. Only then, will the Brazilian public at large start receiving the quality of genetic health care that it is entitled to.

\section{References}

Kessler RG, Sanseverino MTV, Leistner-Segal S, Magalhães JAA and Giugliani R (2008). Prenatal diagnosis of fetal chromosomal abnormalities: Report of an 18-year experience in a Brazilian public hospital. Genet Mol Biol 31:836840 . 